\title{
Kaama-taguste udmurtide ettekujutused elamu kaitsevaimudest
}

\author{
$\underline{\text { Ranus Sadikov }}$
}

Nagu teistelgi rahvastel, nii on ka udmurdi mütoloogias erilisel kohal ettekujutused nn «madalamatest» vaimudest, kelle hulka kuuluvad ka erinevate looduslike või inimese poolt loodud objektide kaitsevaimud või peremehed. Erinevalt «kõrgematest» jumalatest ja vaimudest, kellega inimene harva vahetusse kontakti astub, püsivad «madalamad» vaimud, eriti koduümbruse omad, pidevalt tema tähelepanu all. Seetõttu eksisteerib nende kohta loomulikult ka suur hulk rahvaluulet, eriti memoraate, milles kirjeldatakse inimeste kokkupuuteid nende mütoloogiliste olenditega. Kaamataguste (Bashkortostani ja Permi oblasti) udmurtide seas on sellised memoraadid laialt levinud. Neis peegelduvad nii kogu udmurdi etnosele kui ka antud lokaalsele grupile iseloomulikud ettekujutused madalamatest vaimudest. Kaama-tagustel udmurtidel esinevad elamu ja kõrvalehitistega seotud vaimude kohta käivates memoraatides järgmised tegelased: korkamurt või korkakuzjo, gulbech taka, gidkuzjo, minchokuzjo, kuzjõrsi, zõrtkuzjo. Nagu näha, on kõigi nende vaimude nimed v.a gulbech taka ja kuzjorssi moodustatud ühele või teisele ehitise nimetusele (korka - tare, gid - tall, mincho - saun, zõrt - majapidamine, talu tervikuna) sõnade murt (inimene) või kuzjo (peremees) lisamise teel. Vaatleme nüüd iga mütoloogilist tegelast eraldi.

Elamu/tare kaitsevaimuks on Kaama-taguste udmurtide uskumustes korkamurt või korkakuzjo. Viimast nime kasutatakse sagedamini. V. Vladõkini arvates on udmurdi ühiskonnas toimunud sotsiaalse diferentseerumise mõjul algsed sõna murt abil moodustatud teonüümid tagaplaanile tõrjutud sõna kuzjo abil moodustatud teonüümide poolt (Vladõkin 1994: 97). Siinkohal on huvitav märkida, et loodusobjektidega seotud vaimude nimedes pole seda märgata, näiteks nimetatakse metshaldjat peaaegu alati nimega njulesmurt, väga harva aga njuleskuzjo; vetehaldja nimeks on samuti vumurt ja haruharva vukuzjo. Erinevate rahvaste mütoloogilistes ettekujutustes esines tarehaldjas kõige sagedamini antropomorfsena, mis on iseloomulik ka udmurtidele. N. Pervuhhini järgi kujutasid udmurdid tarehaldjat ette vanataadina, kes alati kannab lambakasukat, karv väljapoole pööratud (Pervuhhin 1888: 90). Samuti arvati, et ta ilmub majaperemehe kujul, nii et teda on võimatu peremehest eristada (Bogajevski 1890: 67). Kaama-taguste udmurtide arvates võis tarehaldjas - korkakuzjo - samuti võtta inimese kuju: ta võis ilmuda valgeis rõivais vanakesena, kusjuures ta võis olla kas mees või naine. Meessoost korkakuzjo puhul võis tares mõnikord kirvehoope kuulda, naissoost tarehaldja puhul aga kostis värtna vurinat. Arvati, et meessoost tarehaldjat omaval pererahval on vedanud, kuna nende tööd-tegemised on alati edukad, nad elavad onnnelikult ja saavad omavahel hästi läbi. Naissoost tarehaldjat aga ei peetud eriti heaks endeks.

Lisaks antropomorfsele esinemisviisile võis tarehaldjas esineda ka looma või mao kujul. Levinud on memoraadid, milles teda kirjeldatakse väikese loomakesena. Mõnikord leitakse tarest sellise haldja karvatuuste. Märgime siinkohal, et ettekujutus väikeloomakujulisest tarehaldjast esineb ka permikomidel (Sherebtsov 1971: 80). Väga sageli kirjeldavad Kaama-tagused udmurdid tarehaldjat maona (nastikuna) tshuzhzõro kõi 1 - see on ilmselt lokaalne eripära, mis pole iseloomulik muudele udmurtidele, igatahes ei ole kirjanduses teateid selle kohta, et udmurdid tundsid maokujulist tarehaldjat. Huvitav on märkida, et ka valgevenelased tunnevad maokujulist tarehaldjat (Baiburin 1983: 109). G. Shkljajevi arvates olid sellised ettekujutused varem omased ka venelastele, tarehaldja kuju ümbermõtestamine nende folklooris (kus ta esineb mitte maona, vaid inimesena) on aga soome-ugri rahvastega toimunud ulatuslike kontaktide tagajärg (Shkljajev 1989: 38). Siiski pole esialgu põhjust tuua mingeid paralleele ettekujutuste vahel maokujulisest tarehaldjast valgevenelastel ja Kaamatagustel udmurtidel. 
Udmurtide arvates hoolitseb tarehaldjas «maja heaolu eest, valvab omapead jäetud lapsi shaitani 2 eest, kes ... armastab lapsi ära viia, aga nende asemele tuua enda omi, kes põhjustavad majas ja peres kõikvõimalikke õnnetusi» (Jakovlev 1915: 260). Nagu näha, on ta mõnikord heaks kaitsevaimuks. Ent sama korkakuzjo võib esineda ka kurja olendina. Arvati, et kui ta ennast kodakondsetele ilmutab, ei tähenda see head. Mõnikord hirmutab ta lapsi. Enamasti näitab ta ennast siis, kui ei salli peremeest. Sellisel juhul võib ta maja maha jätta, aga see toob majarahvale igasuguseid haigusi. Tarehaldja kahepalgeline loomus põhjustas selle, et Kaama-tagused udmurdid suhtusid temasse austusega. Näiteks ei tohtinud majas valjusti käratseda, et teda mitte hirmutada. Votskaja Urada külas (Bashkortostan, Janauli rajoon) toodi talle spetsiaalne ohver - igal kevadel pandi talle pühasenurgas või ja leib lauale sõnadega: «Korkakuzjoje, mone en kõshkatõ» (Minu tarehaldjas, ära mind ehmata). Austav suhtumine temasse ilmneb ka tarehaldja uude majja «meelitamise» rituaalidel. Nimelt kutsuti uude elamusse asudes kaasa ka tarehaldjas, öeldes: "Oido, en kõljõ, mõn mi sjorõ !» (Aidaa, ära jää maha, tule meiega). Sealjuures võeti vanast kohast mulda ja viidi uude elupaika. Seda toimingut ei tohtinud näha ükski kõrvaline inimene. Mõnes külas, näiteks Bolshoi Kachakis (Bashkortostan, Kaltassinski rajoon), meelitati tarehaldjas uude kohta juba enne uue maja ehitamist. Seda tehti sõnadega: «Korkakuzjo, tanji, sjorõs' en kõljõ. Tanji, korka intõ bas'tis'kom» (Tarehaldjas, vot, ära jää siia maha. Vot, võtame [uue] maja koha). Ka sel juhul võeti vanast elupaigast mulda ja viidi uude paika. Kõik need rituaalid pidid tagama tarehaldja ümberasumise vanast elamust uude, et kindlustada seal heaolu. Sama piirkonna Kurgaki külast on fikseeritud huvitav ettekujutus, mille kohaselt igasse uude majja asub elama uus tarehaldjas, nii et vana pole tarvis endaga kaasa kutsuda. Vana maja lammutades püüti kõige alumine palgikord jätta lahti võtmata sellepärast, et see jääks tarehaldja elupaigaks.

Lisaks korkakuzjo 'le eksisteeris Kaama-tagustel udmurtidel teinegi tarehaldjas - gulbech taka (sõnasõnalt 'keldri oinas'). Juba selle mütoloogilise tegelase nimi reedab, et ta nägi välja kui oinas ja elas keldris. Siinjuures on huvitav märkida, et põhjaudmurtidel esines sama tüüpi keldris elav olend, kelle nimeks oli gondõr - karu (Pervuhhin 1888: 91). Müra tekitades ja lapsi hirmutades puskis gulbech taka mõnikord keldris seinu. Ta oli korkakuzjo'st õelam olend. Arvati, et ta võib kodakondsetele erinevaid haigusi saata. Sellistel juhtudel ohverdati talle keldris must oinas. Peamiselt aga toodi selline ohver, mida nimetati samuti gulbech taka, uude majja kolides. Ohvriloom tapeti otse keldris, veri kallati selleks kaevatud auku. Pärast liha keetmist palvetati keldris. Ohvrilooma luud, sisikond, mõnikord ka keetmata jäänud pea, maeti ühes keldrinurgas maha. Teada on ka gulbech taka'le toodud veretu ohver - Kurgaki külas jäeti talle igal aastal keldrinurka valgesse lõuendisse keeratud kruupe ja jahu. Selle mütoloogilise tegelase päritolu on ähmane, kõige tõenäolisemalt on tegemist ohvri personifitseerimisega. On alust arvata, et antud ohvrit (musta karva ohvriloom, ohvriandide maasse kaevamine) ei toodud mitte gulbech taka'le, vaid mu-kõlchin'ile, maa jumalusele, et lunastada tema käest välja maa uue elamu tarvis. Hiljem omandas ohvriloom, keldris tapetud must oinas, iseseisva keldris elava vaimu piirjooned.

Teiseks üleloomulikuks koduümbruse asukaks on Kaama-tagustel udmurtidel gidkuzjo, kes elab laudas ja tallis. Ta võib ennast inimestele ilmutada kas väikese looma või mao kujul, «aga ta ei armasta seda: kui keegi teda näeb, hakkab sel inimesel kari känguma.» (Jakovlev 1915: 260.) Sageli nähakse teda ootamatult lauta või talli sisenedes, mistõttu tuleb selle vältimiseks lauta minnes alati häält teha. Gidkuzjo «vaatab loomade järele, punub oma lemmikhobustel lakka ja tassib neile võõrastelt hobustelt toitu» (samas). Kõigest sellest on näha, et temast sõltub karja edenemine. Kui loomad hakkasid õnduma, arvati, et gidkuzjo ei hoolitse enam nende eest, seepärast viidi tema armuliseks muutmiseks talle anniks leivapäts koos võiga, mis asetati tallis posti otsa (Tshernõhh 1995: 41). Kui gidkuzjo'le ei meeldinud mõni loom, siis piinas ta seda. Kui loomad hommikul laudast väljudes olid higised ja väsinud, arvati, et tema oli see, kes peksis neid öö läbi ja tassis nende sööda teistele loomadele. Ka sel juhul viidi talle lauta ohver, komps jahu, kruubi ja soolaga, öeldes: 
«Pudome en s'iõ, taje s'iõ» (Ära mu loomi söö, söö seda). Nagu tarehaldjas, nii on ka laudahaldjas kahepalgeline, ühelt poolt hoolitseb ta koduloomade eest, teiselt poolt aga piinab ja tapab neid ning viib ära nende sööda.

Järgmiseks koduümbruse vaimuks on minchokuzjo, kes elab saunas. $\underline{3}$ Saunale on paljude rahvaste uskumustes omistatud negatiivseid jooni, seda on peetud paigaks, kus asuvad kurjad jõud (Shabajev 1995: 51). Nii oli ka Kaama-tagustel udmurtidel saunaga teistest õueehitistest erinev suhe, näiteks ei soovitatud sinna minna ilma erilise vajaduseta (Minnijahmetova 1997, 1999). Nagu saun ise, nii oli negatiivsete joontega ka saunahaldjas minchokuzjo. See ilmneb näiteks tõigast, et mõnikord kandis ta nime minchoperi (peri - kuri vaim). Temaga kohtumine ennustas häda. Et seda vältida, tuli sauna sisenedes häält teha, et ta saaks peitu pugeda. Samuti ei soovitatud öösel sauna minna. Mõnede arvates oli saunas vaid üks vaim, teiste meelest elas seal palju kurje vaime, kes mõnikord ennast laulu ja tantsuga lõbustasid ja meelitasid enda juurde juhuslikke möödakäijaid. Samasugused ettekujutused olid iseloomulikud ka teiste piirkondade udmurtidele (Shabajev 1995: 56-57).

XX sajandi esimese veerandi autori K. Jakovlevi väitel arvasid Kaama-tagused udmurdid, et lisaks saunahaldjale elab saunas veel kuzjorrsi (pikajuukseline), kes armastab pesijate kallal tempe teha (Jakovlev 1915: 260). Rohkem teateid selle olendi kohta pole. Siinkohal tuleb märkida, et G. Vereshtshagini järgi kujutasid ka Vjatka kubermangu Sarapuli maakonna udmurdid saunahaldjat ette pikajuukselisena (Vereshtshagin 1889: 85). Arvatavasti tunnistavad kuzjõrsi ja teiste saunahaldjate pikad juuksed nende lähedusest vetehaldjate vumurt'idega, kellel samuti olid pikad juuksed. Viimaseid nähti sageli keskpäeval jõe kaldal oma pikki juukseid kammimas. Teatud sarnasuse sauna- ja vetehaldja vahel on ilmselt põhjustanud sauna seotus veega: saunas puhastas inimene ennast veega nii kehaliselt kui hingeliselt. Mõnikord asusid saunad jõgede või järvede kallastel, see mõjutas samuti sauna- ja vetehaldja vahelist seost. Mitmed rahvad on arvanud, et mingil kindlal ajal asuvad saunadesse elama veega otseselt seotud vaimud, näiteks uskusid permikomid, et sauna tulevad ennast soojendama vetevaimud kul'pijannez (Shabajev 1995: 56). ${ }^{4}$

Väga huvitavaks elamuga seotud üleloomulikuks olendiks on Kaama-tagustel udmurtidel zõrtkuzjo. Zõrt (kirjakeeles jurt) on türgi laen, mis tähendab udmurdi keeles nii elamut kui ka talu - st elamut koos kõigi juurdekuuluvate ehitistega. Kaama-taguste udmurtide arvates «juhtis» zõrtkuzjo kogu majapidamist. Teda iseloomustavaid jooni analüüsides ilmneb suur sarnasus korkakuzjo ja gidkuzjo'ga. Ta võis ennast näidata kas inimese, looma või mao (nastiku) kujul. Temaga kohtumine ei ennustanud samuti midagi head. Kui koduloomad surid, arvati, et zõrtkuzjo ei salli neid. Aga kui haigestus pererahvas, siis arvati, et ta on hoopis ära läinud. U. Holmbergi järgi tundsid sarnast tegelast lisaks Kaama-tagustele ka Kaasani kubermangu udmurdid (Holmberg 1914: 146). Zõrtkuzjo esineb ka türgi rahvaste mütoloogias. Näiteks teatab S. Rudenko, et Loode-Bashkiirias (st Kaamataguste udmurtide vahetus naabruses) usuti jort eiehe nimelise vaimu olemasolu, kes esines nii tare , kui ka talli- ja saunahaldja funktsioonis (Rudenko 1955: 319). Sarnased mütoloogilised tegelased eksisteerisid ka tatarlastel (Bajazitova 1995: 130-132).

Eelneva kokkuvõtteks võib öelda, et elamu ja kõrvalhoonetega seotud üleloomulikest olenditest esinevad Kaama-tagustel udmurtidel järgmised: korkakuzjo - tarehaldjas, gulbech taka - tarehaldjas keldris elava oinana, gidkuzjo - lauda või talli haldjas, minchokuzjo - saunahaldjas, kuzjõrsi - pikajuukseline saunahaldjas. Kui korkakuzjo ja gidkuzjo esinevad nii heade kui ka kurjade olenditena, siis gulbech taka, minchokuzjo ja kuzjõrsi on läbinisti kurjad vaimud. Peale eri hoonetega seotud vaimude uskusid Kaama-tagused udmurdid ka kogu majapidamise kaitsevaimu zõrtkuzjo olemasolu, kelles aga on ühinenud nii tare-, kui ka tallihaldjale iseloomulikud jooned. Olemuselt on temagi ühtaegu nii hea kui ka kuri vaim.

Tõlkis Aado Lintrop 


\section{Kasutatud kirjandus}

Baiburin, A. K. 1983. Zhilishshe v obrjadah i predstavlenijah vostotshnõh slavjan. Leningrad. Bajazitova, F. S. 1995. Tatar halkõnõn beirem hem konkuresh jolalarõ. Kaasan Bogajevski, P. M. 1890. Otsherki religioznõh predstavlenii votjakov. Etnografitsheskoje obozrenije no. 4, Moskva, 1k. 42-70.

Holmberg, U. 1914. Permalaisten uskonto. Suomen suvun uskonnot IV. Porvoo. Jakovlev, K. 1915. Vorovanija i religioznõe obrjadõ votjakov Birskogo i Osinskogo ujezdov. Vestnik Orenburskogo uzhebnogo okruga, no. 6-7, 1k. 258-265.

Minnijahmetova, T. G. 1997. Traditsionnaja banja zakamskih udmurtov. Rossija i Vostok: Traditsionnaja kul'tura, etnokul'turnõje etnosotsial'nõje protsessõ. Materialõ IV Mezhdunarodnoi nautshnoi konferentsii "Rossija i Vostok: problemõ vzaimodeistvija". Omsk, 1k. 59-60.

Minnijahmetova, T. 1999. Ohverdamine Kaama-tagustel udmurtidel. Mäetagused nr 9. Tartu. lk 5061.

Pervuhhin, N. G. 1888 Eskizõ predanii i bõta inorodtsev Glazovskogo ujezda. Eskiz 1. Vjatka.

Rudenko, S. I. 1955 Bashkirõ. Istoriko-etnografitsheskije otsherki. Moskva-Leningrad.

Shabajev, J. Shabajeva, N. 1995 Banja v verovanijah i predstavlenijah russkih, komi i udmurtov.

Finno-ugrovedenije no. 2, 1k. 51-63.

Shkljajev, G. K. 1989 Obrjadõ i poverija udmurtov, svjazannõje s zhilishshem. Fol'klor $i$ etnografija udmurtov: obrjadõ, obõtshai, pover'ja. Izhevsk.

Zherebtsov, L. N. Krestjanskoje zhilishshe v Komi ASSR. Sõktõkvar.

Tshernõhh, A. V. 1995 Buiskije udmurtõ. Etnografitsheskij otsherk. Perm.

Vereshtshagin, G. 1889 Votjaki Sarapul'skogo ujezda Vjatskoi gubernii. Zapiski Imperatorskogo

Russkogo geografitsheskogo obshestva, t. XIV võp. 3. Sankt-Peterburg.

Vladõkin, V. E. 1994 Religiozno-mifologitsheskaja kartina mira udmurtov. Izhevsk.

\section{Kommentaarid}

1. Sõnastik annab selle, sõna-sõnalt 'kollase peaga mao' vasteks vaskussi, siiski võib see piirkonniti tähendada ka nastikut (kollakad laigud pea tagaosas.) (Tõlk.)

2. Udm. 'kurat, saatan, kuri vaim'.

3. Kirjakeeles on saun muncho, vastav üleloomulik olend kannab mujal Udmurtias nime munchokuzo (Tõlk).

4. $k u l^{\prime}$ - komi k. 'kurat, vetevaim'. Siinkohal tuleb tähelepanu juhtida tõsiasjale, et ka udmurdid tundsid selliseid üleloomulikke veega seotud olendeid, keda arvati talvisel pööriajal saunadesse elama asuvat. Neid nimetati vozho'deks, pööriaega aga vozho-ajaks (vozhodõr). Näiteks on autorigi poolt korduvalt tsiteeritud N. Pervuhhin kirjutanud vetehaldja kohta: "Suvisel vozho-ajal ta magab, aga talvisel tuleb (enne jõule) veest maale ja saadab enamasti aega mööda saunades, kuigi võib ka tänaval vastu tullaà» (Pervuhhin 1888: 75). Sedasorti teadetele tähelepanu pööramata jätkab autor V. Vladõkini suunda, mis vozho'sid käsitleb vaid seoses rahvakalendriga, mainides, et talvine pööriaeg lõpeb pühaga jö võle sulton (mis mui- 
de kas järgneb pühale nimega vozho kel'an - vozho ärasaatmine - või kannab ise sama nime), mille kohta arvati, et «sel päeval kogu «roojasus» - vozhoos - läheb vee alla» (Vladõkin 1994: 229). Ometi on rohkearvuliselt teateid selle kohta, kuidas ööl vastu 6. jaanuarit käisid külanoored vozho'sid peletades saunast sauna. Tõsi küll, komme oli rohkem levinud põhjaudmurtide seas, nagu ka ettekujutused vozhodest. Komid nimetasid vastavaid tegelasi enamasti tshuud'ideks (vt Lintrop, A. Udmurdi rahvausundi piirjooni, Tartu 1993, 1k 60-65.) 